Schouten, B., Merten, H., Spreeuwenberg, P.M.M., Nanayakkara, P.W.B., Wagner, C. The Incidence and Preventability of Adverse Events in Older Acutely Admitted Patients: A Longitudinal Study With 4292 Patient Records. Journal of Patient Safety: 17(3)

$\begin{array}{lll}\text { Postprint version } & : & 1.0 \\ \text { Journal website } & : & \text { https://journals.Iww.com/journalpatientsafety/Citation/2021/04000/The } \\ & & \text { Incidence_and_Preventability_of_Adverse_Events.2.aspx } \\ \text { Pubmed link } & : & \text { https://pubmed.ncbi.nIm.nih.gov/33734205/ } \\ \text { DOI } & : & 10.1097 / P T S .0000000000000727\end{array}$

This is a Nivel certified Post Print, more info at nivel.nl

\title{
The Incidence and Preventability of Adverse Events in Older Acutely Admitted Patients: A Longitudinal Study With 4292 Patient Records
}

\author{
Bo Schouten, ${ }^{*}$ Hanneke Merten, ${ }^{*}$ Peter M.M. Spreeuwenberg,,+ Prabath \\ W.B. Nanayakkara* ${ }^{*}$, Cordula Wagner, ${ }^{* \dagger}$ \\ * Department of Public and Occupational Health, Amsterdam UMC, Vrije Universiteit Amsterdam, \\ Amsterdam Public Health Research Institute, Amsterdam \\ + Netherlands Institute for Health Services Research (NIVEL), Utrecht; \\ ¥ Department of Internal Medicine, Section Acute Medicine, Amsterdam UMC, Vrije Universiteit \\ Amsterdam, Amsterdam Public Health Research Institute, Amsterdam, the Netherlands.
}

Objectives: Acute care crowding is a global issue, jeopardizing patient safety. An important cause of crowding is the growing number of older, vulnerable, and complex patients. This group is at higher risk of experiencing (preventable) adverse events (AEs) than younger patients.

This study aimed to identify the incidence, preventability, nature, and prevention strategies of AEs in older patients during an acute hospital admission and to assess changes over time.

Methods: We analyzed data of 4292 acutely admitted patients $(70+)$ who died in the hospital, using data of a multicenter Dutch AE record review study $(2008,2012$, 2016).Multilevel logistic regression analyses were performed to adjust for patient-mix differences and clustering on department/hospital level per year.

Results: The incidence of AEs in this group declined significantly $(\chi 2(1)=8.78, P=0.003)$ from $10.7 \%$ (95\% confidence interval $[\mathrm{Cl}]=8.2-13.9)$ in $2008,7.4 \%(95 \% \mathrm{Cl}=5.6-9.7)$ in 2012 , to $7.2 \%(95 \% \mathrm{Cl}=5.5-9.3)$ in 2016 . The relative preventability showed a significant parabolic trend $(\chi 2(1)=4.86, P=0.027)$, from $46.2 \%(95 \% \mathrm{Cl}=34.1-58.7)$, to $32.4 \%$ (95\% $\mathrm{Cl}=21.1-46.1)$, to $44.6 \%(95 \% \mathrm{Cl}=32-58)$. Adverse events were often related to medication (26.3\% in 2008, 35.1\% in 2012, and $39.5 \%$ in 2016), and the preventability in AEs related to diagnosis was highest ( $88.3 \%, 70.8 \%$, and $79.9 \%)$. 
Schouten, B., Merten, H., Spreeuwenberg, P.M.M., Nanayakkara, P.W.B., Wagner, C. The Incidence and Preventability of Adverse Events in Older Acutely Admitted Patients: A Longitudinal Study With 4292 Patient Records. Journal of Patient Safety: 17(3)

Conclusions: The incidence of AEs in older acutely admitted patients declined over the years; however, the preventability increased again after an initial decline. This could be related to crowding or increasing complexity in the acute care chain. Further monitoring and improvement in (preventable) AE rates are necessary to pinpoint areas of improvement to make hospital care for this vulnerable group safer.

Acute care represents a large and essential element of hospital care and plays a vital role in preventing disability and death. Compared with younger patients, older patients present more frequently at emergency departments (EDs), get admitted at higher rates, require more resources, have higher risk of readmissions, and have longer length of stay (LoS). ${ }^{1,2}$ The demand on acute and emergency care has been increasing and will continue doing so, creating major challenges for healthcare professionals and policy makers. One of the important causes is the growing number of older, vulnerable, and complex patients. This crowding of acute care has been recognized as a global issue, putting patient safety at risk. ${ }^{3}$

Patient safety is fundamental for quality of care; therefore, many countries have investigated the adverse event $(\mathrm{AE})$ rates in their hospitals. ${ }^{4} \mathrm{An} \mathrm{AE}$ is defined as an unintended injury, resulting in prolonged hospital stay, disability, or death, and is caused by healthcare management issues rather than the disease. ${ }^{5} \mathrm{An} \mathrm{AE}$ is considered preventable when caused by healthcare professionals not following the accepted practice and/or by inadequacies in the healthcare system. ${ }^{6}$ In the Netherlands, AE rates are monitored structurally every 4 years, by conducting retrospective record review studies. $^{7-9}$

Multiple studies show that older patients are at higher risk to experience (preventable) AEs during a hospital admission, compared with younger patients. ${ }^{6,10-15}$ Furthermore, Merten et al $^{16}(2013)$ showed that the consequences of (preventable) AEs are more severe in older patients. The higher (preventable) AE rates in older patients are argued to be related to the severity of their condition, frailty, comorbidity, atypical disease presentation, polypharmacy, complexity of care, and longer hospital stay, rather than to high age alone. ${ }^{13,14,17}$

Earlier international AE research encompasses study samples of both elective and acute admissions and is mostly based on data collected before the largest acute care crowding challenges emerged. Results are contradicting; some studies report higher AE rates and more severe consequences for acutely admitted patients. ${ }^{7,8,12,18,19}$ However, other studies did not find higher AE rates for acute admissions compared with elective admissions. ${ }^{9,20,21}$ Because of the growing challenges in the acute care chain, this is an important research area, to get more insight into the variability of care processes and the resilience of healthcare professionals and organizations.

Furthermore, it is unclear whether there have been changes over time in AE rates, which is necessary to evaluate whether patient safety for older acutely admitted patients has improved. Change over time is particularly important to assess as the Dutch national patient safety program, with a special focus for frail elderly patients (designed and implemented after the first Dutch AE study) ran from 2008 to $2012 .{ }^{22}$ No new national patient safety programs were implemented after that. In the United States, comparable patient safety programs were enrolled: the 100,000 lives campaign (2005$2006)^{23}$ and 5 million lives campaign (2006-2008). ${ }^{24}$ These programs in the Netherlands and the United States had a positive impact on the national AE rates. ${ }^{8,23,25}$ However, it seems that the attention for patient safety reduced after these comprehensive programs ended, as shown by the stagnation of reduction in preventable AE rates in the Netherlands. ${ }^{9}$ To keep improving, it is important to start thinking about the next step in patient safety worldwide. Therefore, to pinpoint the most relevant areas for improvement, this study aims to identify the incidence, preventability, nature, and prevention strategies of AEs in older patients during an acute hospital admission and asses changes over time $(2008,2012$, and 2016). 
Schouten, B., Merten, H., Spreeuwenberg, P.M.M., Nanayakkara, P.W.B., Wagner, C. The Incidence and Preventability of Adverse Events in Older Acutely Admitted Patients: A Longitudinal Study With 4292 Patient Records. Journal of Patient Safety: 17(3)

\section{Methods}

We analyzed a subsample (consisting of acutely admitted older patients, 70+) of the data of 3 national Dutch patient record review studies (2008, 2011/2012, and 2015/2016; hereafter, 2008, 2012 , 2016). An admission was considered acute when unplanned. The comprehensive design and results of the independent studies have been described elsewhere. ${ }^{7-9}$ All studies have been granted approval by the ethics committee of the Amsterdam University Medical Center, the Netherlands. This section starts by describing the design of the initial Dutch AE studies, followed by the methods of the current study.

\section{Study Design and Setting of the Initial AE Studies}

The random sample consisted of 20 hospitals in 2008, 20 hospitals in 2012 and 19 hospitals in 2016.All sampleswere stratified for hospital type (university, tertiary teaching, and general) and region. Hospitals with less than 200 beds were excluded in all samples. The university hospitals were overrepresented in all samples, weights have been added to correct for this in all analyses.

Patients admitted to a psychiatric or obstetric department and children younger than 1 year were excluded in all samples. A sample of 200 (2008 and 2012) and 150 (2016) patient records were randomly selected per hospital. In the 2008 and 2012 study, half of examined records were of discharged patients and half of deceased patients. However, research indicates that AEs are more prevalent in deceased patients 21,26 and that examining records of deceased patients gives us a higher power and therefore a more accurate estimation of (preventable) AEs. ${ }^{8}$ Therefore, only records of deceased patients were examined in the 2016 study. For these reasons, we included only the records of deceased patients in the analysis of the subset of acutely admitted older people in the current study.

\section{Record Review Process of the Initial AE Studies}

The record review researchmethod is considered to be the most effective method to assess $A E$ rates. ${ }^{27-29}$ In the Dutch AE studies, trained and experienced external nurses and physicians (medical specialties: surgery, internal medicine, and neurology) reviewed the nursing, medical, and, if available, outpatient records. The reviewing nurses and physicians could not review records of the hospitals they were or had been employed at. In the first stage, a nurse screened all records by using a list of triggers indicating potential AEs (e.g., unplanned admission in the year before index admission, adverse drug reaction). The trigger list has been evaluated and used in multiple international studies. ${ }^{6,10-12}$ Records with at least 1 trigger present in the first stage were eligible for further review by a physician in the second stage. The presence, preventability, nature, and prevention strategies of AEswere determined in the second stage. An AE was defined by 3 criteria ${ }^{6}$ :

○ Unintended injury

- Resulting in prolonged hospital stay, disability, or death

- Caused by healthcare management, rather than the disease

An AE was considered potentially preventable when systematic analysis of the events indicated that certain measures could have prevented the AE. A potentially preventable AE was defined as an error in healthcare management because of failure to follow accepted practice, at an individual and/or system level. ${ }^{5}$ The preventability was scored on a 6-point Likert scale, and a score of 4 or higher, which indicated a chance of $50 \%$ or more injury being caused by healthcare management, was considered potentially preventable (full Likert scale: 1 , (almost) no evidence for being caused by healthcare management; 2 , slight tomoderate evidence; 3 , not likely (less than $50 / 50$, but "close call"); 4, more likely (more than 50/50, but 'close call'); 5, strong evidence; and 6, (almost) certain evidence). 
Schouten, B., Merten, H., Spreeuwenberg, P.M.M., Nanayakkara, P.W.B., Wagner, C. The Incidence and Preventability of Adverse Events in Older Acutely Admitted Patients: A Longitudinal Study With 4292 Patient Records. Journal of Patient Safety: 17(3)

The reliability was tested in all studies by having a random sample of $5 \%$ of the records reviewed twice independently, in both the first and second stage. The record reviews were found to be reliable, and methods and results of reliability tests have been described elsewhere. ${ }^{7-9,30}$

\section{[Figure 1]}

\section{Nature and Prevention Strategies of AEs of the Initial AE Studies}

The nature of AEs was reviewed for all AEs and classified into 7 categories of clinical processes (diagnostic, surgery, nonsurgical medical procedure, medication, other clinical management, discharge, and other). Reviewers selected the clinical process to which the AE was predominantly related. In addition, the reviewers could select 1 or multiple potential prevention strategies for preventable AEs. The prevention strategies were classified into 10 categories (technology/equipment, procedures, information/communication, training, motivation, quality assurance/peer review, scaling up, evaluation, financial investment, and personnel). ${ }^{31}$

\section{Statistical Analysis of the Current Study}

Our subsample consisted of records of older acutely admitted patients who died during the admission in all 3 study periods. Figure 1 shows a flowchart on how this subsample was achieved from the total sample.

Baseline characteristics, weighted for hospital type,were calculated using StataSE 14 (StataCorp, 2015, Stata Statistical Software: Release 14; StataCorp LP, College Station, TX).

The record review studies consisted of hierarchal data, with multiple levels: the individual patient, the hospital department, the hospital, and time. The observations in the datawere not independent; therefore, multilevel analyses were required to adjust for clustering on the department and hospital level per year.

Multilevel logistic regression analyses, using MLwiN Version 2.30 (Centre for MultilevelModeling, University of Bristol), were performed to calculate the incidence of AEs, the preventability, the different categories within the nature, and prevention strategies and to assess overall change over time in all these outcome variables. $P$ values of 0.05 or less were considered statistically significant. To adjust for the possibility that change over time was influenced by differences in patient mix, the following confounding variables were added to the multilevel model: sex, admission to a surgical ward, and International Statistical Classification of Diseases, Ninth Revision, diagnosis group. These confounding variables are equal to those of the multilevel models in previous studies. ${ }^{20,21,32,33}$ All variables in the multilevel models were standardized to reference values of Dutch hospital admissions.

As some categories within the nature and prevention strategies variables represented small numbers, they were not robust for multilevel analysis. Therefore, we chose to combine some of the smaller categories and performed the analysis on the relevant categories. For nature of $A E$, the relevant categories were as follows: diagnostic, surgery, nonsurgical medical procedure, medication, and others. For prevention strategies, the categories were as follows: procedures, information/communication, training, motivation, quality assurance/peer review, evaluation, and others.

\section{Results}

\section{Study Sample}

For the 3 study samples (2008, 2012, and 2016), a total of 4292 medical records of acutely admitted older patients, deceased at the hospital, were reviewed. Table 1 shows the baseline 
Schouten, B., Merten, H., Spreeuwenberg, P.M.M., Nanayakkara, P.W.B., Wagner, C. The Incidence and Preventability of Adverse Events in Older Acutely Admitted Patients: A Longitudinal Study With 4292 Patient Records. Journal of Patient Safety: 17(3)

characteristics per year, and of the total sample, all variables in the table were added to the multilevel model as confounding variables.

\section{Adverse Events and Preventability}

We found a total of 457 AEs in 428 patients. The numbers of AEs per year were 165, 127, and 165 (2008, 2012, and 2016, respectively), in 150, 122, and 156 patients. Figure 2 shows the trend over the years in $A E$ incidence and the relative preventability within the category for the total group and per age category (70-79, 80-89, and 90+).

The incidence ofAEs in the total group shows an overall significant decline over the years from $10.7 \%$ (95\% confidence interval $[\mathrm{Cl}]=8.2-13.9)$ in 2008 , to $7.4 \%(95 \% \mathrm{Cl}=5.6-9.7)$ in 2012 , to $7.2 \%$ $(95 \% \mathrm{Cl}=5.5-9.3)$ in 2016. The overall declining linear trend was also found for the 70 to 79 and 80 to 89 age categories.

The relative preventability showed a significant parabolic trend from $46.2 \%(95 \% \mathrm{Cl}=34.1-58.7)$ in 2008 , to $32.4 \%(95 \% \mathrm{Cl}=21.1-46.1)$ in 2012 , to $44.6 \%(95 \% \mathrm{Cl}=32-58)$ in 2016 . This corresponds with an overall incidence of preventable AEs of $4.5 \%(95 \% \mathrm{Cl}=3.0-6.5)$ in $2008,2.2 \%(95 \% \mathrm{Cl}=1.5-$ $3.4)$ in 2012 , and $3.0 \%(95 \% \mathrm{Cl}=2.0-4.3)$ in 2016 . The parabolic overall trend was also found for the 80 to 89 age category.

\section{Nature}

Figure 3 shows the distribution of the nature of AEs and the relative preventability within the categories over the years. Adverse events in older acutely admitted patients are predominantly related to medication (26.3\% in $2008,35.1 \%$ in 2012 , and $39.5 \%$ in 2016 ).

The diagnostic category shows a high relative preventability $(88.3 \%$ in $2008,70.8 \%$ in 2012 , and $79.9 \%$ in 2016). The relative preventability of the surgery-related AEs shows a significant parabolic trend $(38.4 \%$ in $2008,8.9 \%$ in 2012 , and $63.6 \%$ in 2016$)$.

\section{Prevention Strategies}

In 9 cases, no prevention strategies were selected, and these were therefore excluded from this analysis. Table 2 shows the distribution of prevention strategies and trends over the years.

In most potentially preventable AEs, quality assurance/peer review was selected as a prevention strategy. Evaluation showed a significant parabolic trend and information/communication showed a significant increasing linear trend.

Table 3 provides examples of AEs, their preventability, nature, and prevention strategies in acutely admitted older patients.

\section{[Table 1]}

\section{Discussion}

This study describes the incidence, preventability, nature, and prevention strategies of AEs over time in older acutely admitted patients. We found a significantly overall declining incidence of AEs of 10.7\% in 2008, 7.4\% in 2012, and 7.2\%in 2016. However, the relative preventability of AEs in our sample showed a significant parabolic trend from $46.2 \%$ in $2008,32.4 \%$ in 2012 , to $44.6 \%$ in 2016 , which corresponds with an incidence of preventable AEs of $4.5 \%$ in $2008,2.2 \%$ in 2012 , and $3.0 \%$ in 2016. In addition, although in our sample the relative preventability in 2016 returned to the level of 2008 , this was not found in the total Dutch sample (including patients all aged $>1$ ) in which the preventability remained stable from 2012 to $2016 .{ }^{9}$ This indicates that the patient safety for older acutely admitted patients is at a higher risk than other, less frail patient groups. In the Netherlands, there is an increasing proportion of older people, who live independently instead of in care homes. This group keeps increasing in age but also in multimorbidity, polypharmacy, and frailty, which 
Schouten, B., Merten, H., Spreeuwenberg, P.M.M., Nanayakkara, P.W.B., Wagner, C. The Incidence and Preventability of Adverse Events in Older Acutely Admitted Patients: A Longitudinal Study With 4292 Patient Records. Journal of Patient Safety: 17(3)

results inmore visits to the ED and acute admissions to the hospital every year. ${ }^{34,35}$ This makes acute healthcare for this group increasingly complex, potentially resulting in the increase of the incidence of potentially preventable AEs.

Disaggregated by age category, we found that the 70 to 79 and 80 to 89 age categories showed an equivalent overall declining trend inAE incidence as our total sample of acutely admitted older patients, but the $90+$ category did not. This could be due to the high complexity and frailty in this oldest group of older patients. They are less resilient than the younger groups of older patients, potentially causing them to be more vulnerable. ${ }^{36-38}$

Adverse events in older acutely admitted patients are predominantly related to medication. The high percentage medication-related AEs (MRAEs) is in line with a previous studies, finding high percentages ofMRAEs in patients who died in the hospital, acute admissions, and older patients. ${ }^{16,39-}$ ${ }^{42}$ The high percentage of MRAEs could be explained by the increasing age,multimorbidity, and polypharmacy of this group, therefore being increasingly prone to errors. ${ }^{4-45}$ The clinical process with highest preventability is the category diagnostic, which is in line with previous research that found high percentages of preventable diagnostic AEs (DAEs), ${ }^{10,46}$ particularly in acute admissions. The high preventability is possibly explained by the fact that DAEs received less attention (i.e., analysis and improvement initiatives) compared with AEs related to other clinical processes (i.e., surgery and medication) over the years, which could be due to the fact that diagnostic errors are relatively complex to define and to measure. ${ }^{47}$

\section{[Figure 2]}

It is remarkable that the relative preventability in the surgical category showed a significant parabolic trend over the years, with a strong decrease from 2008 to 2012, but increase from 2012 to 2016. When looking into the open text fields of the data, we see that in 2008 and 2016, many of the surgical preventable AEs were related to hip fractures, which seems to be less in 2012. Previous research showed that older hospitalized hip fracture patients are at high risk to experience a preventable AE. ${ }^{48}$ Therefore, the larger number of hip fracture patients in our 2008 and particularly 2016 sample might explain some of the parabolic trend in preventability.

A strong aspect of this study is the use of a standardized and internationally acknowledged record review method, allowing comparison with results of similar AE studies. This researchmethod is considered to be themost effective method to assessAE rates. ${ }^{27-29}$ All reviewers had extensive clinical experience. In addition, this study contains a large total number of systematically reviewed patient records. The study is representative for the acute admissions of deceased older patients in Dutch hospitals, as we used a random, stratified, and diverse sample.

Despite the strengths of this study, there are some limitations that should be considered. First, this research method is subject to hindsight bias. Because the reviewers know the (negative) outcomes, judgment can be influenced, possibly causing overestimation of preventability. ${ }^{49}$ Second, reviewers only have access to information available in the patient record, registered by hospital personnel, for $\mathrm{AE}$ assessment. These records do not always contain sufficient in-depth and relevant information regarding the presence of $A E s$, their preventability, nature, and possible prevention strategies. Neither does the patient record always give a complete reflection of treatment risks made in the (multidisciplinary) treatment team. Furthermore, the amount of information available might have changed over the years, because of the start of using electronic patient records. The third limitation is the interrater reliability. Although measures have been taken over the years to optimize the record review process and to assure an interrater reliability as high as possible, the individual experience and perspectives of the reviewers will never align completely. ${ }^{9}$ 
Schouten, B., Merten, H., Spreeuwenberg, P.M.M., Nanayakkara, P.W.B., Wagner, C. The Incidence and Preventability of Adverse Events in Older Acutely Admitted Patients: A Longitudinal Study With 4292 Patient Records. Journal of Patient Safety: 17(3)

\section{[Figure 3]}

\section{[Table 2]}

This study shows that further improvement in (preventable) AE rates in older acutely admitted patients is necessary, to make hospital care for this group safer. To achieve this, our recommendations are to focus on "quality assurance and peer review," for example, by using machine learning techniques to detect safety risks. ${ }^{50,51}$ Examples of potential interventions for all prevention strategies are shown in Table 1 in the supplement. Moreover, especially in the 2016 study, the prevention strategy "evaluation" emerged as an important prevention strategy. An aspect of "evaluation" is the patient safety culture among healthcare professionals. We recommend to assess (with, i.e., Patient Safety Culture Survey (COMPaZ), ${ }^{52}$ Patient Safety Climate in Healthcare Organizations (PSCHO) survey, ${ }^{53}$ Hospital Survey on Patient Safety Culture (HSOPS) 54 ) and improve this with, for example, team training, simulations, etc. ${ }^{55}$

Furthermore, we recommend to continue monitoring (preventable) AEs and the trends in this group, especially because the preventability has shown a parabolic trend, which could keep increasing in the future. Literature shows that LoS is shortening worldwide, even for the older and complex patients, and we also see this change in our data. ${ }^{56}$ It remains unclear how this may have affected the incidence of AEs and potentially preventable AEs. It is plausible that with a shorter LoS, people are exposed less to a risk of error in the hospital, which could explain the decreasing trend in AE incidence. However, it is also plausible that with a shorter LoS, more (e.g., conducting diagnostic tests, treatment, etc.) has to be done within a shorter timeframe, therefore causing the performance of healthcare professions to be more rushed. This could potentially explain the parabolic trend in the relative preventability of AEs. The next step should be to encourage healthcare professionals to actively involve the older acutely admitted patient and decide together about diagnostics, treatment, and admission, based on the patients' wishes, preferences, and goals.

\section{[Table 3]}

Finally, we recommend to focus onMRAEs, as these represent high percentages and seem to increase over the years. Polypharmacy is relatively common among older patients, so some of the strategies could be to focus on reducing the number of newly prescribed medications, to discontinue medication that is no longer necessary, to improve the already existing and implemented medication verification systems, ${ }^{22,57}$ and to adapt these systems to the increasing prevalence of polypharmacy.

\section{Conclusions}

This study shows that although the incidence of AEs in older acutely admitted patients declined over the years, the relative preventability does not showthis trend. This could be related to the crowding in acute care and/or the increasing complexity of this group (due to increasing age, frailty, multimorbidity, and polypharmacy). However, future research is needed to examine whether these relationships are truly existing and causal.

Moreover, further monitoring and improvement in (preventable) AE rates in older acutely admitted patients are necessary, to make hospital care for this vulnerable and complex group safer. Improvement initiatives (i.e., quality assurance, peer review, evaluation, and focus on MRAEs and DAEs) are recommended. 
Schouten, B., Merten, H., Spreeuwenberg, P.M.M., Nanayakkara, P.W.B., Wagner, C. The Incidence and Preventability of Adverse Events in Older Acutely Admitted Patients: A Longitudinal Study With 4292 Patient Records. Journal of Patient Safety: 17(3)

\section{References}

1. Aminzadeh F, DalzielWB. Older adults in the emergency department: a systematic review of patterns of use, adverse outcomes, and effectiveness of interventions. Annals of emergency medicine. 2002;39:238-247.

2. Hastings $\mathrm{SN}$, Heflin MT. A systematic review of interventions to improve outcomes for elders discharged from the emergency department. Acad Emerg Med. 2005;12:978-986.

3. Morley C, UnwinM, PetersonGM, et al. Emergency department crowding: a systematic review of causes, consequences and solutions. PLoS One. 2018;13:e0203316.

4. Panagioti M, Khan K, Keers RN, et al. Prevalence, severity, and nature of preventable patient harm across medical care settings: systematic review and meta-analysis. BMJ. 2019;366:14185.

5. Ca Wagner, van der WG. Voor een goed begrip: bevordering patiëntveiligheid vraagt om heldere definitie. Medisch Contact. 2005;60: 1888-1891.

6. Brennan TA, Leape LL, Laird NM, et al. Incidence of adverse events and negligence in hospitalized patients. Results of the Harvard Medical Practice Study I. N Engl JMed. 1991;324:370-376.

7. Langelaan $M$, Baines RJ, Broekens MA, Siemerink KM, van de Steeg $L$, Asscheman $H$, de Bruijne MC, Wagner C. Monitor zorggerelateerde schade 2008: dossieronderzoek in Nederlandse ziekenhuizen. 2010. Available at:

https://nivel.nl/sites/default/files/bestanden/Rapportzorggerelateerde-schade.pdf. Accessed June 17, 2020.

8. Langelaan M, de Bruijne MC, Baines RJ, Broekens MA, Hammink K, Schilp J, Verweij L, Asscheman H, Wagner C. Monitor Zorggerelateerde Schade 2011/2012: dossieronderzoek in Nederlandse ziekenhuizen. 2013. Available at:

https://www.nivel.nl/sites/default/files/bestanden/monitor_zorggerelateerde_schade_2011_20 12.pdf. Accessed June 17, 2020.

9. Langelaan M, Broekens MA, de Bruijne MC, et al. Monitor zorggerelateerde schade 2015/2016: dossieronderzoek bij overleden patiënten in Nederlandse ziekenhuizen. 2017. Available at: https://www.nivel.nl/sites/default/files/bestanden/Rapport_Monitor_Zorggerelateerde_Schade _2017.pdf. Accessed June 17, 2020.

10. Baker GR, Norton PG, Flintoft V, et al. The Canadian Adverse Events Study: the incidence of adverse events among hospital patients in Canada. CMAJ. 2004;170:1678-1686.

11. Davis $P$, Lay-Yee R, Briant $R$, et al. Adverse events in New Zealand public hospitals I: occurrence and impact. N Z Med J. 2002;115:U271.

12. Wilson RM, Runciman WB, Gibberd RW, et al. Quality in Australian Health Care Study. Med J Aust. 1996;164:754.

13. Thomas EJ, Brennan TA. Incidence and types of preventable adverse events in elderly patients: population based reviewofmedical records. BMJ. 2000; 320:741-744.

14. Sari AB, Cracknell A, Sheldon TA. Incidence, preventability and consequences of adverse events in older people: results of a retrospective case-note review. Age and ageing. 2008;37:265-269.

15. Szlejf C, Farfel JM, Curiati JA, et al. Medical adverse events in elderly hospitalized patients: a prospective study. Clinics (Sao Paulo). 2012;67: 1247-1252.

16. Merten $\mathrm{H}$, ZegersM, de BruijneMC, et al. Scale, nature, preventability and causes of adverse events in hospitalised older patients. Age Ageing. 2013; 42:87-93.

17. Long SJ, Brown KF, Ames D, et al.What is known about adverse events in older medical hospital inpatients? A systematic reviewof the literature. IntJ Qual Health Care. 2013;25:542-554.

18. Sommella L, de Waure C, Ferriero AM, et al. The incidence of adverse events in an Italian acute care hospital: findings of a two-stage method in a retrospective cohort study. BMC Health Serv Res. 2014;14:358. 
Schouten, B., Merten, H., Spreeuwenberg, P.M.M., Nanayakkara, P.W.B., Wagner, C. The Incidence and Preventability of Adverse Events in Older Acutely Admitted Patients: A Longitudinal Study With 4292 Patient Records. Journal of Patient Safety: 17(3)

19. Baines RJ, Langelaan M, de Bruijne MC, et al. Is researching adverse events in hospital deaths a good way to describe patient safety in hospitals: a retrospective patient record review study. BMJ Open. 2015; 5:e007380.

20. ZegersM, De Bruijne MC, Spreeuwenberg $P$, et al. Variation in the rates of adverse events between hospitals and hospital departments. Int J Qual Health Care. 2011;23:126-133.

21. Baines RJ, Langelaan M, de Bruijne MC, et al. Changes in adverse event rates in hospitals over time: a longitudinal retrospective patient record review study. BMJ Qual Saf. 2013;22:290-298.

22. Carolien de Blok EK, Schilp Janneke, Wagner Cordula. Implementatie VMS veiligheidsprogramma. Nivel. 2013. Available at:

https://www.nivel.nl/sites/default/files/bestanden/Rapport-ImplementatieVMSVeiligheidsprogramma.pdf. Accessed June 17, 2020.

23. Wachter RM, Pronovost PJ. The 100,000 Lives Campaign: a scientific and policy review. Jt Comm J Qual Patient Saf. 2006;32:621-627.

24. McCannon CJ, Hackbarth AD, Griffin FA. Miles to go: an introduction to the 5 Million Lives Campaign. Jt Comm J Qual Patient Saf. 2007;33:477-484.

25. IHI. 5 Million Lives Campaign. 2008. Available at: http://www.ihi.org/engage/initiatives/completed/5millionlivescampaign/Pages/default.aspx. Accessed June 3, 2020.

26. Zegers $M$, de Bruijne $M C$,Wagner $C$, et al. Adverse events and potentially preventable deaths in Dutch hospitals: results of a retrospective patient record review study. Qual Saf Health Care. 2009;18:297-302.

27. Michel P, Quenon JL, de Sarasqueta AM, et al. Comparison of threemethods for estimating rates of adverse events and rates of preventable adverse events in acute care hospitals. BMJ. 2004;328:199-190.

28. Shojania KG, Thomas EJ. Trends in adverse events over time: why are we not improving? BMJ. 2013;22:273-277.

29. Thomas EJ, Petersen LA. Measuring errors and adverse events in health care. J Gen InternMed. 2003;18:61-67.

30. ZegersM, deBruijneMC,Wagner $C$, et al. Design of a retrospective patient record study on the occurrence of adverse events among patients in Dutch hospitals. BMC Health Serv Res. 2007;7:27.

31. Smits $M$, Zegers $M$, Groenewegen PP, et al. Exploring the causes of adverse events in hospitals and potential prevention strategies. Qual Saf Health Care. 2010;19:e5.

32. Baines $R$, Langelaan $M$, de Bruijne $M$, et al. How effective are patient safety initiatives? $A$ retrospective patient record review study of changes to patient safety over time. BMJ Qual Saf. 2015;24:561-571.

33. Moesker MJ, Schutijser B, de Groot JF, et al. Occurrence of antithrombotic related adverse events in hospitalized patients: incidence and clinical context between 2008 and 2016. J ClinMed. 2019;8:E839.

34. kousemaeker EWGd. Onderzoek naar een duurzame inrichting spoedzorg keten voor ouderen. 2017. Available at: https://www.actiz.nl/stream/actiz-onderzoek-naar-duurzame-inrichtingspoedzorgketen-voor-ouderendoor-fluent. Accessed June 1, 2020.

35. NZa. Monitor acute zorg 2018. Nederlandse Zorgautoriteit. 2019. Available at: https://puc.overheid.nl/nza/doc/PUC_260889_22/1/.Accessed June 17, 2020.

36. Nogueira SL, Ribeiro RC, Rosado LE, et al. Determinant factors of functional status among the oldest old. Rev Bras Fisioter. 2010;14:322-329.

37. Lai $X$, Zhu H, Huo X, et al. Polypharmacy in the oldest old ( $>/=80$ years of age) patients in China: a cross-sectional study. BMC geriatrics. 2018;18:64.

38. Parker MG, Thorslund $M$. Health trends in the elderly population: getting better and getting worse. The Gerontologist. 2007;47:150-158. 
Schouten, B., Merten, H., Spreeuwenberg, P.M.M., Nanayakkara, P.W.B., Wagner, C. The Incidence and Preventability of Adverse Events in Older Acutely Admitted Patients: A Longitudinal Study With 4292 Patient Records. Journal of Patient Safety: 17(3)

39. Gray SL, Sager M, Lestico MR, et al. Adverse drug events in hospitalized elderly. J Gerontol A Biol Sci Med Sci. 1998;53:M59-M63.

40. Pretorius RW, Gataric G, Swedlund SK, et al. Reducing the risk of adverse drug events in older adults. Am Fam Physician. 2013;87:331-336.

41. Tangiisuran B, Wright J, Van der Cammen T, et al. Adverse drug reactions in elderly: challenges in identification and improving preventative strategies. Age and ageing. 2009;38:358-359.

42. Damen NL, Baines R, Wagner C, et al. Medication-related adverse events during hospitalization: a retrospective patient record review study in the Netherlands. Pharmacoepidemiol Drug Saf. 2017;26:32-39.

43. Cooper JW. Adverse drug reaction-related hospitalizations of nursing facility patients: a 4-year study. South Med J. 1999;92:485-490.

44. Frazier SC. Health outcomes and polypharmacy in elderly individuals: an integrated literature review. J Gerontol Nurs. 2005;31:4-11.

45. Hohl CM, Dankoff J, Colacone A, et al. Polypharmacy, adverse drug-related events, and potential adverse drug interactions in elderly patients presenting to an emergency department. Ann EmergMed. 2001;38: 666-671.

46. Thomas EJ, StuddertDM, Burstin HR, et al. Incidence and types of adverse events and negligent care in Utah and Colorado. Med Care. 2000;38: 261-271.

47. Zwaan $\mathrm{L}$, Singh $\mathrm{H}$. The challenges in defining and measuring diagnostic error. Diagnosis (Berl). 2015;2:97-103.

48. MertenH, Johannesma PC, Lubberding S, et al. High risk of adverse events in hospitalised hip fracture patients of 65 years and older: results of a retrospective record review study. BMJ Open. 2015;5:e006663.

49. Henriksen K, Kaplan H. Hindsight bias, outcome knowledge and adaptive learning. Qual Saf Health Care. 2003;12:ii46-ii50.

50. Menard T, Barmaz Y, Koneswarakantha B, et al. Enabling data-driven clinical quality assurance: predicting adverse event reporting in clinical trials using machine learning. Drug Saf. 2019;42:1045-1053.

51. Marella WM, Sparnon E, Finley E. Screening electronic health record-related patient safety reports using machine learning. J Pat Saf. 2017;13:31-36.

52. Smits M, Christiaans-Dingelhoff I, Wagner C, et al. De validiteit van COMPaZ. TSG. 2007;85:105114.

53. Singer $\mathrm{S}$, Meterko M, Baker L, et al.Workforce perceptions of hospital safety culture: development and validation of the patient safety climate in healthcare organizations survey. Health Serv Res. 2007;42:1999-2021.

54. Sorra JS, Dyer N. Multilevel psychometric properties of the AHRQ hospital survey on patient safety culture. BMC Health Serv Res. 2010;10:199.

55. Gross B, Rusin L, Kiesewetter J, et al. Crew resource management training in healthcare: a systematic review of intervention design, training conditions and evaluation. BMJ Open. 2019;9:e025247.

56. OECD. Health at a Glance. 2017: OECD Indicators, OECD Publishing, Paris; 2017. Available at: https://doi.org/10.1787/health_glance-2017-en. Accessed June 1, 2020.

57. VMS. Medicatieverificatie bij opname en ontslag. 2008. Available at: https://www.vmszorg.nl/wpcontent/uploads/2017/03/web_2008.0101_praktijkgids_medverificatie.pdf. Accessed June 17, 2020. 
Schouten, B., Merten, H., Spreeuwenberg, P.M.M., Nanayakkara, P.W.B., Wagner, C. The Incidence and Preventability of Adverse Events in Older Acutely Admitted Patients: A Longitudinal Study With 4292 Patient Records. Journal of Patient Safety: 17(3)

\section{[Tables and figures]}

Figure 1: Flowchart of the sample

10917 records in the total sample (deceased and discharged patients)

20084023 records

20114048 records

20162846 records
4039 records excluded from discharged patients

20082016 records

20112023 records

20160 records

899 records excluded from non-acute admissions

2008299 records

2011250 records

2016350 records

1687 records excluded from patients $<70$ years old and missing age $(n=3)$

2008494 records

2011508 records

2016685 records

4292 included records of acutely admitted older patients

20081214 records

20111267 records

20161811 records 
Schouten, B., Merten, H., Spreeuwenberg, P.M.M., Nanayakkara, P.W.B., Wagner, C. The Incidence and Preventability of Adverse Events in Older Acutely Admitted Patients: A Longitudinal Study With 4292 Patient Records. Journal of Patient Safety: 17(3)

\section{Table 1 Baseline Characteristics}

\begin{tabular}{|c|c|c|c|c|c|}
\hline Patient Characteristics & 2008 & & 2012 & 2016 & Total \\
\hline Acutely admitted patients, $\mathrm{n}$ & 1214 & & 1267 & 1811 & 4292 \\
\hline Sex, male, \%* & 51.8 & & 51.1 & 51.2 & 51.3 \\
\hline Age, median (IQR), y & $81(76-86)$ & & $82(77-87)$ & $83(77-88)$ & $82(77-87)$ \\
\hline $70-79, \% *$ & 41.6 & & 38.4 & 34.9 & 35.4 \\
\hline $80-89, \% *$ & 46.0 & & 46.0 & 48.4 & 48.2 \\
\hline $90+, \% *$ & 12.5 & & 15.6 & 16.7 & 16.4 \\
\hline Admission Characteristics & & 2008 & 2012 & 2016 & total \\
\hline \multicolumn{6}{|l|}{ Hospital type, \% } \\
\hline General & & 57.4 & 46.6 & 45.3 & 49.1 \\
\hline Tertiary teaching & & 30.0 & 40.9 & 40.3 & 37.6 \\
\hline University & & 12.6 & 12.6 & 14.4 & 13.3 \\
\hline LoS, median (IQR) & & $7(3-14)$ & $5(2-12)$ & $4(1-10)$ & $5(2-11)$ \\
\hline \multicolumn{6}{|l|}{ Admission department, \%* } \\
\hline Surgery & & 11.2 & 10.8 & 10.7 & 10.7 \\
\hline Cardiology & & 17.9 & 14.9 & 13.9 & 14.2 \\
\hline Internal medicine & & 28.7 & 28.1 & 31.7 & 31.3 \\
\hline Orthopedics & & 1.6 & 1.7 & 1.2 & 1.2 \\
\hline Neurology & & 13.5 & 11.5 & 11.1 & 11.3 \\
\hline Pulmonary disease & & 13.2 & 15.6 & 13.2 & 13.3 \\
\hline Urology & & 0.8 & 1.2 & 0.6 & 0.6 \\
\hline Other & & 13.1 & 16.3 & 17.7 & 17.3 \\
\hline \multicolumn{6}{|l|}{ ICD-9, \%* } \\
\hline Infectious and parasitic diseases & & 3.3 & 5.3 & 6.4 & 6.1 \\
\hline Neoplasms & & 12.6 & 14.2 & 9.4 & 9.9 \\
\hline Endocrine & & 3 & 1.5 & 1.3 & 1.5 \\
\hline Heart and vascular diseases & & 37.8 & 34.1 & 30.2 & 30.9 \\
\hline Respiratory diseases & & 18 & 16.8 & 21.4 & 20.9 \\
\hline Gastrointestinal diseases & & 6.7 & 7.6 & 7.2 & 7.2 \\
\hline Urogenital diseases & & 3.1 & 3.5 & 5.2 & 5 \\
\hline Symptoms, signs, and ill-defined conditions & & 4.6 & 5.2 & 7.1 & 6.8 \\
\hline Injury and poisoning & & 6.3 & 6.9 & 8.4 & 8.2 \\
\hline Other & & 4.5 & 4.8 & 3.5 & 3.6 \\
\hline
\end{tabular}


Schouten, B., Merten, H., Spreeuwenberg, P.M.M., Nanayakkara, P.W.B., Wagner, C. The Incidence and Preventability of Adverse Events in Older Acutely Admitted Patients: A Longitudinal Study With 4292 Patient Records. Journal of Patient Safety: 17(3)

Figure 2 Incidence and the relative preventability within the category of AEs over the 506 years in the total sample and per age category. Adjusted for clustering in the data and patient-mix differences over the years. asignificant decline in incidence. Total: $(\chi 2(1)=8.78, P=0.003)$, 70-79: $(\chi 2(1)=5.35, P=0.021)$, and 80-89: $(\chi 2(1)=4.06 P=0.044)$. bStable trend in incidence: $90+:(\chi 2(2)=1.47, P=0.48)$. cSignificant parabolic trend in relative preventability. Total: $(\chi 2(1)=4.86, P=0.027)$, and $80-89:(\chi 2(1)=11.3, P=0.0008)$. dStable trend in relative preventability: $70-79(\chi 2(2)=0.27, P=0.873)$ and $90+(\chi 2(2)=0.80, P=$ 0.67).

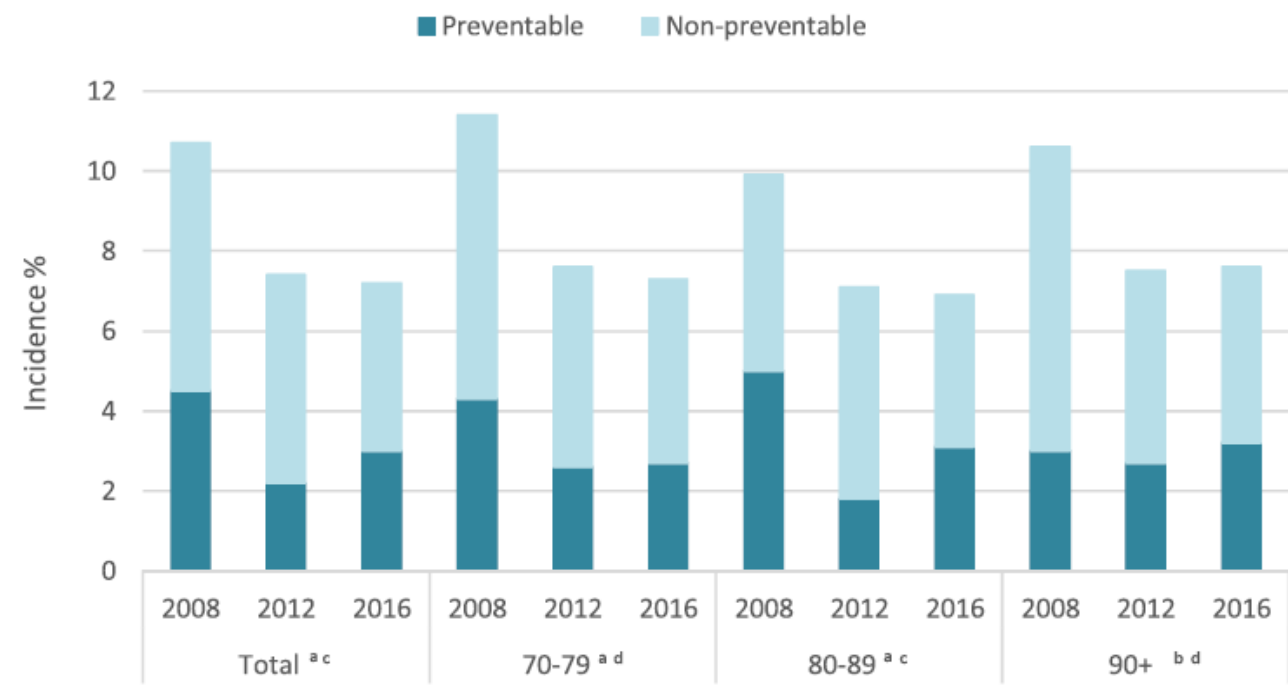

Figure 3 Nature and relative preventability within the category of AEs over the years. a aAdjusted for clustering in the data and patient-mix differences over the years. bStable trend in incidence. Diagnostic: $(\chi 2(2)=0.86, P=0.651)$, Surgery: $(\chi 2(2)=2.52, P=0.284)$, nonsurgical medical procedure: $(\chi 2(2)=1.57, P=0.456)$, medication: $(\chi 2(2)=3.95, P=0.139)$, and other: $(\chi 2(2)$ $=0.8, P=0.67)$. cSignificant parabolic trend in relative preventability. Surgery: $(\chi 2(2)=$ 16.24, $P=0.0003)$. dStable trend in relative preventability. Diagnostic: $(\chi 2(2)=1.78, P=$ $0.411)$, nonsurgical medical procedure: $(\chi 2(2)=0.36, P=0.835)$, medication: $(\chi 2(2)=2.67, P$ $=0.263)$, and other: $(\chi 2(2)=0.75, P=0.687)$.

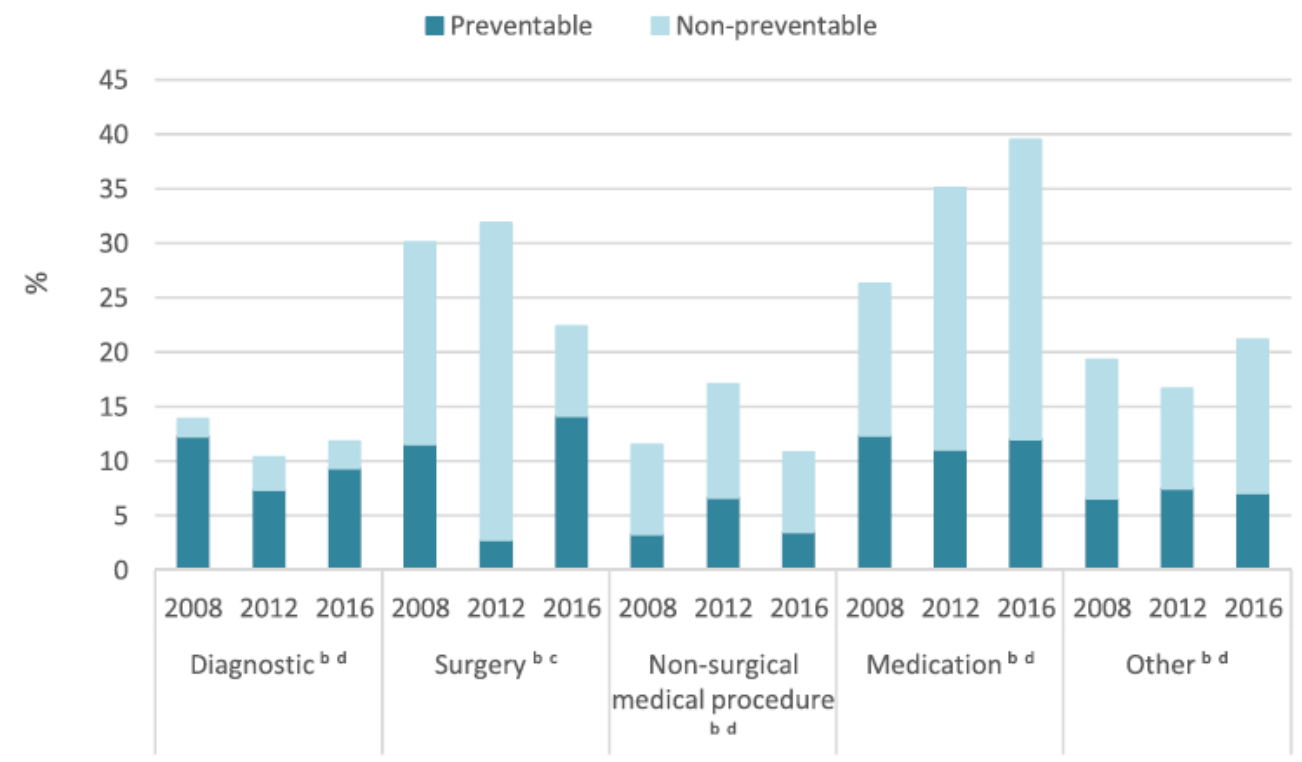


Schouten, B., Merten, H., Spreeuwenberg, P.M.M., Nanayakkara, P.W.B., Wagner, C. The Incidence and Preventability of Adverse Events in Older Acutely Admitted Patients: A Longitudinal Study With 4292 Patient Records. Journal of Patient Safety: 17(3)

Table 2 Prevention Strategies Over the Years

\begin{tabular}{|c|c|c|c|c|}
\hline Prevention Strategies, \% of Preventable AEs (N = 197)* & 2008 & 2012 & 2016 & Trend Over Years \\
\hline $\begin{array}{l}\text { Quality assurance/peer review } \\
\text { Continuously monitoring of data quality based on prespecified } \\
\text { standards and assessment of healthcare professional's performance } \\
\text { by individuals in the same field }\end{array}$ & 69.3 & 65.6 & 65.7 & Stable $\left(\chi^{2}(2)=0.26 P=0.878\right)$ \\
\hline $\begin{array}{l}\text { Evaluation }^{\dagger} \\
\text { Evaluating the current way of behaving regarding safety }\end{array}$ & 49.7 & 35.6 & 60.8 & Parabolic trend $\left(\chi^{2}(1)=4.02 P=0.04\right)$ \\
\hline $\begin{array}{l}\text { Training } \\
\text { Improving (re)training programs for skills needed }\end{array}$ & 44.3 & 57.7 & 55.1 & Stable $\left(\chi^{2}(2)=1.77 P=0.413\right)$ \\
\hline $\begin{array}{l}\text { Procedures } \\
\text { Completing or improving formal and informal procedures }\end{array}$ & 42.7 & 37.3 & 33.1 & Stable $\left(\chi^{2}(2)=1.03 P=0.298\right)$ \\
\hline $\begin{array}{l}\text { Motivation } \\
\text { Increasing the level of voluntary obedience to generally accepted } \\
\text { rules by positive behavior modification }\end{array}$ & 27.7 & 25.1 & 27.3 & Stable $\left(\chi^{2}(2)=0.07 P=0.966\right)$ \\
\hline $\begin{array}{l}\text { Information/communication }{ }^{\dagger} \\
\text { Completing or improving available sources of information and } \\
\text { communication structures }\end{array}$ & 7 & 9.2 & 16.9 & $\begin{array}{l}\text { Increasing linear trend } \\
\qquad\left(\chi^{2}(1)=5.77 P=0.016\right)\end{array}$ \\
\hline $\begin{array}{l}\text { Other } \\
\text { Technology, scaling up, financial investment, personnel }\end{array}$ & 2.8 & 0.6 & 1.5 & Stable $\left(\chi^{2}(2)=2.34 P=0.31\right)$ \\
\hline
\end{tabular}

Table 3 Examples of AEs in Acutely Admitted Older Patients

\begin{tabular}{|c|c|c|c|}
\hline $\mathbf{A E}$ & Preventable & Nature & Prevention Strategy \\
\hline Neutropenic sepsis after chemotherapy and death & No & Medication & - \\
\hline $\begin{array}{l}\text { Death after femoral head replacement due to pulmonary embolism } \\
\text { despite prophylaxis }\end{array}$ & No & Surgical & - \\
\hline Urinary tract infection after timely removal of bladder catheter & No & $\begin{array}{l}\text { Nonsurgical medical } \\
\text { procedure }\end{array}$ & - \\
\hline Death due to late diagnosis ruptured spleen and intestinal ischemia & Yes & Diagnostic & Evaluation \\
\hline $\begin{array}{l}\text { Died after thigh amputation due to late diagnosis vascular obstruction. } \\
\text { Presented to ED } 5 \text { d earlier with similar complaints. }\end{array}$ & Yes & Diagnostic & $\begin{array}{c}\text { Information/communication } \\
\text { Training } \\
\text { Evaluation }\end{array}$ \\
\hline Exchange of dobutamine and dopamine & Yes & Medication & $\begin{array}{l}\text { Procedures } \\
\text { Quality assurance/peer review }\end{array}$ \\
\hline $\begin{array}{l}\text { Anticoagulants continued after decision to abstain with bowel bleeding } \\
\text { at INR }>8\end{array}$ & Yes & Medication & Evaluation \\
\hline $\begin{array}{l}\text { Inadequate treatment: while not indicated, the external bile duct drain } \\
\text { had been removed }\end{array}$ & Yes & $\begin{array}{l}\text { Nonsurgical medical } \\
\text { procedure }\end{array}$ & Quality assurance/peer review \\
\hline $\begin{array}{l}\text { Sepsis and death due to small intestine perforation after surgery } \\
\text { femoral fracture }\end{array}$ & yes & Surgical & $\begin{array}{c}\text { Motivation } \\
\text { Quality assurance/peer review } \\
\text { Evaluation }\end{array}$ \\
\hline
\end{tabular}

